\title{
EFEITOS DE FONTES DE BORO NO DESENVOLVIMENTO RADICULAR DO GIRASSOL (Helianthus annuus) EM RIZOTRONS
}

\author{
Paulo R.C. Castro \\ Silvio Tavares ${ }^{2}$ \\ Luciana Bertolotti ${ }^{3}$ \\ Raphael G. $\mathbf{A b e}^{3}$ \\ Tsuioshi Yamada ${ }^{4}$
}

\section{RESUMO}

O objetivo deste trabalho foi verificar o efeito de diferentes fontes de boro, aplicadas em mistura com o substrato, no desenvolvimento inicial do sistema radicular de girassol (Helianthus annuus) em rizotrons sob condições de casa de vegetação. Os substratos foram preparados separadamente com ácido bórico, ulexita, Borogran e Yoorin B, além do controle, sendo que a concentração de boro no substrato foi da ordem de $3 \mathrm{ppm}$, correspondente a $6 \mathrm{~kg}$. ha ${ }^{-1}$ do micronutriente. O substrato utilizado recebeu correção de $750 \mathrm{mg}$ de Yoorin e de $250 \mathrm{mg}$ de sulfato de amônio por $\mathrm{kg}$ de terra, tendo sido mantido em condições próximas da capacidade de campo. Foram utilizados rizotrons com altura de $0,59 \mathrm{~m}$ e diâmetro de $0,24 \mathrm{~m}$, com capacidade para 13,2 L de substrato, para os cinco tratamentos, com cinco repetições cada, perfazendo 25 rizotrons delineamento inteiramente casualizado. Após a semeadura em 20/06/02, o crescimento da raiz principal foi determinado de 2 a 12 dias após a semeadura (DAS). Verificou-se que Borogran promoveu maiores incrementos no

\footnotetext{
${ }^{1}$ Departamento de Ciências Biológicas, ESALQ-USP, Caixa Postal 09, CEP 13418-900 Piracicaba-SP, Brasil.

${ }^{2}$ Curso de Pós-Graduação em Fitotecnia, ESALQ-USP.

${ }^{3}$ Curso de Engenharia Agronômica, ESALQ-USP

${ }^{4}$ Diretor da Potafos.
} 
desenvolvimento radicular, sendo que Yoorin B diminuiu o crescimento em relação ao controle.

Palavras-chave: Helianthus annuus, Borogran, crescimento da raiz.

\section{ABSTRACT}

\section{EFFECTS OF BORON SOURCES ON ROOTS GROWTH OF SUNFLOWER (Helianthus annuus) ON RIZOTRONS}

The purpose of this research was to test the effects of several boron sources, applied in mixture with the substrate, on initial development of roots of sunflower (Helianthus annuus) in rizotrons. The substrates were prepared isolately with boric acid, ulexite, Borogran, Yoorin B, and control. Boron concentration on substrate was $3 \mathrm{ppm}$ corresponding to $6 \mathrm{~kg} \cdot \mathrm{ha}^{-1}$ of the element. The substrate used was corrected with $750 \mathrm{mg}$ of Yoorin and $250 \mathrm{mg}$ of ammonium sulphate by $\mathrm{kg}$ of soil, and this soil was maintained at field capacity of water. It was used rizotrons with $0,59 \mathrm{~m}$ height and $0,24 \mathrm{~m}$ diameter, with capacity for 13,2 L of substrate, for five treatments with five replications, with 25 rizotrons, in a completely randomized design. After sowing June 20, 2002, the growth of the main root was established from 2 to 12 days after sowing (DAS). It was verified that Borogran promoted growth of the root and Yoorin B reduced the growth compared with the controls.

Key-words: Helianthus annuus, Borogran, root development.

\section{INTRODUÇÃO}

O boro é um dos micronutrientes mais extensamente aplicado nas plantas cultivadas. Sua exigência pela alfafa, crucíferas e alguns sistemas radiculares é bem conhecida (Tisdale \& Nelson, 1966).

$\mathrm{O}$ ácido bórico $\left(\mathrm{H}_{3} \mathrm{BO}_{3}\right)$ contém $17 \%$ de boro; é um composto cristalino com solubilidade de $5,04 \mathrm{~g} / 100 \mathrm{~g}$ de água a $20^{\circ} \mathrm{C}$, recomendado para fertirrigação e adubação foliar. A ulexita $\left(\mathrm{Na}_{2} \mathrm{O} \cdot 2 \mathrm{CaO} \cdot \mathrm{B}_{2} \mathrm{O}_{3} \cdot 16 \mathrm{H}_{2} \mathrm{O}\right)$ possui $9 \%$ de boro,insolúvel em água,contendo ainda 12 a $14 \%$ de 
cálcio. Borogran está constituído de $10 \%$ de boro e de $10 \%$ de enxofre. $\mathrm{O}$ Yoorin $\mathrm{B}$ contém $15,5 \%$ de $\mathrm{P}_{2} \mathrm{O}_{5}$ solúvel em ácido cítrico, $7,0 \%$ de magnésio, $20,8 \%$ de cálcio, $0,4 \%$ de boro e $25 \%$ de silício.

Boro é um elemento freqüentemente mencionado em discussões sobre a formação de raízes adventícias (Rehm, 1937, citado por Gorter, 1958). Estudos iniciais revelaram que o boro estimula o enraizamento de estacas mais pela promoção do desenvolvimento das raízes do que pela indução do início dos primórdios radiculares (Hemberg, 1951).

O micronutriente boro pode existir na concentração de $0,05 \mathrm{ppm}$, na solução nutritiva do solo e é essencial para a formação de auxinas nas plantas (Eaton, 1940). Gauch \& Dugger Jr. (1953) mostraram evidências convincentes, da hipótese de que uma via do boro envolve reações com açúcares, para formar um complexo borato-açúcar ionizável, que passa através das membranas celulares mais rapidamente do que moléculas de açúcar não ionizadas, sem o borato, sendo translocado mais rapidamente para células de crescimento. Os autores sugerem que, sintomas de deficiência do boro são uma expressão da deficiência de açúcar no câmbio, botões florais, caule e raízes, e que, na ausência de boro, carboidratos podem ficar concentrados nas regiões da sua síntese.

Segundo Weiser (1959) o boro tem sido observado como estimulador do enraizamento em várias estacas de ornamentais híbridas, como é o caso da Clematis. Neste trabalho, o autor verificou que a porcentagem de enraizamento de estacas de Clematis foi grandemente aumentada pela utilização de IBA $50 \mathrm{ppm}+\mathrm{B} 50 \mathrm{ppm}$, por 12 horas em imersão, quando comparada com o uso de IBA 50 ppm sozinho, com os respectivos valores de $86,7 \%$ e $55,6 \%$ de enraizamento. Estes dados estão de acordo com a afirmação de Gorter (1958) de que a associação do boro com auxinas, aumenta a produção de raízes.

Já autores como Eaton (1940), Murray et al. (1957) e Weiser \& Blaney (1960) afirmaram que a presença do boro não influi na iniciação do enraizamento das estacas, mas é essencial para seu posterior crescimento. Folhas de plantas deficientes em boro apresentaram, comparativamente, maiores concentrações de açúcares e amido; contudo, a concentração nos ramos mostrou-se baixa. Isso indica que a presença de boro em quantidade adequada é necessária à translocação dos açúcares das folhas para os ramos. Utilizando-se sacarose e boro juntos e em 
separado, em solução nutritiva, observou-se estreita dependência da translocação do açúcar em presença de boro (Gauch \& Dugger Jr., 1953).

De acordo com Neales (1960) o crescimento das raízes de todas as espécies estudadas em seu trabalho, foi significativamente reduzido pela ausência de boro no meio de crescimento. Com isso, o autor evidenciou o fato do boro ser necessário para a divisão celular em meristemas primários e secundários, em muitas diferentes espécies.

A deficiência do micronutriente boro, pode acarretar distúrbios no desenvolvimento dos tecidos meristemáticos, como extremidades de raiz e de partes aéreas das plantas ou tecidos de câmbio. Portanto, um contínuo fornecimento de boro é necessário para manter a atividade meristemática. A razão para este requerimento ainda não é conhecida, mas tem sido verificado que o boro é necessário para síntese de bases nitrogenadas como uracil.Uracil é um componente essencial do RNA e se estiver ausente, o RNA não pode ser formado, afetando desta maneira, a síntese protéica. A síntese de ácido ribonucléico, a formação de ribose e a síntese de proteínas são os processos mais importantes nos tecidos meristemáticos. Se eles são alterados por carência de boro, todo o processo de crescimento meristemático fica prejudicado (Mengel \& Kirkby, 1982).

Coke \& Whittington (1968) sugeriram que a necrose em pontos de crescimento deficientes em boro é causada por acúmulo de auxina. $O$ boro protege o sistema IAA-oxidase, por formar complexos com inibidores do sistema IAA-oxidase. Assim, o acúmulo de auxinas e de compostos fenólicos deve ser a causa primária da necrose em plantas com deficiência de boro.

A associação de boro com auxinas aumenta o enraizamento de estacas, porém quando existe grande quantidade de ácido indolilacético (IAA) endógeno na estaca, não é necessária a atividade do cofator (Jackson \& Harney, 1970).

Dentre as substâncias inorgânicas que afetam a produção de raízes, o boro se apresenta como o mais relevante (Gorter, 1958). Uma das diversas hipóteses sugeridas para o papel do boro no metabolismo das plantas é a manutenção dos níveis de hormônios. Segundo Coke \& Whittington (1968), plantas deficientes em boro, têm excesso de 
hormônios endógenos, portanto, o acréscimo de auxinas sintéticas aumentaria a deficiência deste micronutriente.

Middleton et al. (1978) e Jarvis et al. (1983a) relataram uma correlação entre níveis de boro e fotoperíodo. Assim, estacas com folhas na luz, podem se tornar deficientes em boro mais cedo que estacas com folhas no escuro. Da mesma forma, sem o fornecimento de boro exógeno, nenhuma raiz aparece em estacas que crescem na luz. Essas diferenças entre tecidos sob luz e escuro, poderiam ser explicadas pelo alto nível de metabólitos secundários presentes nos tecidos crescidos sob luz. Muitos desses, como ácidos fenólicos, têm altas constantes de associação com borato e, podem assim, se combinar com o boro endógeno e tornar real sua severa limitação.

Foi verificado em estacas de Vigna radiata que os primórdios radiculares foram iniciados pela ação de auxinas, mas o crescimento, a partir do início do desenvolvimento, era dependente da presença de boro (Middleton et al., 1978). O papel obrigatório do boro no crescimento radicular parece real, mas a maneira pela qual ele atua nos processos metabólicos que afetam o enraizamento (Haissig, 1986), assim como ao nível de toda planta, ainda não é bem conhecida (Lewis, 1980). Alguns trabalhos sugerem que o boro afeta o enraizamento pela regulação dos níveis de auxinas endógenas através da ativação da IAA-oxidase (Jarvis et al., 1983b, 1984).

Radiação induziu exigência por boro para o enraizamento de Phaseolus aureus (Jarvis \& Ali, 1984). Em tecidos com boro limitado, a radiação pode criar uma relativa deficiência, reduzindo a habilidade do tecido em responder ao estímulo do enraizamento. Condições de escuro durante o período de enraizamento superam parcialmente o requerimento por uma fonte de boro. Jarvis \& Ali (1984) consideram a possibilidade de que a radiação pode atuar no sentido de tornar o boro não disponível através de modificações no metabolismo desse micronutriente, por meio da síntese de orto dihidroxi fenóis, providos de grupamentos cis-hidroxi, capazes de formar complexos com o boro. Foi demonstrado que o cálcio pode incrementar a resposta em enraizamento nas estacas tratadas com boro (Jarvis \& Yasmin, 1985).

Jarvis et al. (1983c) avaliaram o papel de poliaminas no desenvolvimento de raízes adventícias em estacas caulinares de Vigna 
radiata $\mathrm{cv}$. Berkin. Verificaram que a aplicação de espermina sozinha, ou com ácido indolbutírico (IBA), possui um efeito estimulatório na formação dessas raízes, na presença de boro. Parece que para o crescimento inicial de $V$. radiata sob luminosidade, o boro é um requerimento essencial para o efeito do IBA na indução dos primórdios radiculares e para subseqüente desenvolvimento das raízes (Middleton et al. 1978; Jarvis et al. 1983a.).

Altman \& Bachrach (1981) observaram aumentos no teor de putrescina e de espermidina em hipocótilos estaqueados de $V$. radiata tratados em IBA. Possivelmente essas estacas continham níveis limitados de boro.

Para estacas de $V$. radiata sob luminosidade, o boro parece ser um pré-requisito para o enraizamento (Middleton et al., 1978), o qual, na presença de IBA é também estimulado pelas folhas de estacas (Middleton et al., 1980). De acordo com Jarvis et al. (1983b) a poliamina espermina aumentou o número de raízes em estacas de $V$. radiata, somente na presença de boro. Em estacas foliares de $V$. radiata cv. Taiman Select 3, a promoção de enraizamento pela aplicação de poliaminas ou IBA não depende da aplicação exógena de boro (Shyr \& Kao, 1985), o que sugere que as estacas contém suficiente boro endógeno.

A possibilidade de o boro regular os níveis de auxina endógena durante o desenvolvimento da raiz é ainda discutida, tendo em vista não ser o boro exógeno exigido até 48 horas depois de as estacas serem colocadas em solução de auxina, podendo ser suprimido a qualquer tempo prévio, inclusive durante o período de iniciação radicular (Jarvis et al., 1983a.).

Kersten (1990) verificou que a aplicação de boro, em estacas de ameixeira (Prunus salicina), aumentou seu teor de triptofano, quando comparadas com o controle.

Ono et al. (1992), estudando o enraizamento de estacas de camélia, observaram que tratamentos de IBA e ácido naftalenacético (NAA) com a adição de boro, apresentaram maior número de estacas enraizadas, do que aqueles compostos só com auxinas. $\mathrm{O}$ melhor tratamento encontrado foi IBA $100 \mathrm{mg} / \mathrm{L}$ + boro $150 \mathrm{ì} / \mathrm{ml}$, por 18 horas, em embebição (83\%), quando comparado com IBA $100 \mathrm{mg} / \mathrm{L}(40 \%)$ e controle $(33 \%)$. 
Esses dados estão de acordo com Ribas (1993) que, estudando o enraizamento de estacas herbáceas de macadâmia, verificou que tratamentos com IBA $200 \mathrm{ppm}$ + boro $150 \mathrm{ig} / \mathrm{ml}$, por 16 horas em embebição, foram os melhores para promover a indução radicular $(10,94 \%)$, quando comparados com IBA $200 \mathrm{ppm}(1,56 \%)$ e controle $(0 \%)$.

Esse trabalho teve por objetivo verificar o efeito de diferentes fontes de boro (ácido bórico, ulexita, Borogran e Yoorin B) aplicadas em mistura com o substrato, no desenvolvimento inicial do sistema radicular de girassol, observado em rizotrons.

\section{MATERIAL E MÉTODOS}

Para estabelecer o efeito de diferentes fontes de boro, aplicadas em mistura com o substrato, no desenvolvimento inicial do sistema radicular de girassol (Helianthus annuus) em rizotrons, sob condições de casa de vegetação, prepararam-se isoladamente os substratos com ácido bórico $\left(\mathrm{H}_{3} \mathrm{BO}_{3}\right)$, ulexita $\left(\mathrm{Na}_{2} \mathrm{O} \cdot 2 \mathrm{CaO} \cdot \mathrm{B}_{2} \mathrm{O}_{3} \cdot 16 \mathrm{H}_{2} \mathrm{O}\right)$, Borogran $(10 \% \mathrm{~B}+10 \% \mathrm{~S})$ e Yoorin $\mathrm{B}\left(15,5 \% \mathrm{P}_{2} \mathrm{O}_{5}+7,0 \% \mathrm{Mg}+20,0 \% \mathrm{Ca}+0,4 \% \mathrm{~B}\right.$ $+25 \% \mathrm{Si}$ ), além do controle (testemunha). A concentração de boro nos substratos foi de $3 \mathrm{ppm}$, correspondente a $6 \mathrm{~kg} \cdot \mathrm{ha}^{-1}$ do micronutriente. Os substratos utilizados receberam correção com $750 \mathrm{mg}$ de Yoorin e de $250 \mathrm{mg}$ de sulfato de amônio por $\mathrm{kg}$ de terra. Os substratos foram mantidos em condições próximas da capacidade de campo, no que se refere a disponibilidade de água.

Foram utilizados rizotrons com altura de $0,59 \mathrm{~m}$ e diâmetro de $0,24 \mathrm{~m}$, com capacidade para $13,2 \mathrm{~L}$ de substrato, para os cinco tratamentos, com cinco repetições cada, perfazendo 25 rizotrons num delineamento inteiramente casualizado.

Após a semeadura, em 20/06/02, o crescimento da raiz principal foi determinado com caneta de retroprojeção sobre plástico transparente mantido sobre o vidro dos rizotrons. As notações das raízes foram realizadas sempre às $10 \mathrm{~h} 00$ da manhã do $2^{\circ}$ ao $12^{\circ}$. DAS, quando raízes atingiram o fundo de rizotrons.

Os plásticos foram então retirados para a mensuração das raízes, o crescimento diário foi analisado estatisticamente, tendo-se utilizado o 
teste Duncan (5\%) para comparação das médias (Pimentel-Gomes, 2000). Os tratamentos mais e menos eficientes foram apresentados gratificamente em relação ao controle. O comprimento radicular total, no $12^{\circ}$. DAS, foi também analisado estatisticamente.

\section{RESULTADOS E DISCUSSÃO}

Os resultados obtidos encontram-se apresentados na Tabela 1. Observamos que Borogran promoveu maior crescimento radicular aos 2,3 , e 9 DAS. Também verificamos que ulexita aumentou o crescimento da raiz principal 3 DAS. Ácido bórico incrementou o desenvolvimento radicular 9 DAS. Foi verificado que o boro estimulou o enraizamento de estacas através da promoção do desenvolvimento radicular (Hemberg, 1951). Yoorin B diminuiu o crescimento da raiz principal aos 3 e 4 DAS e aumentou aos 11 DAS.

Tabela 1. Comprimento da raiz principal de girassol dos 2 aos 12 dias após a semeadura DAS em rizotrons contendo substrato com diferentes fontes de boro (3ppm).

\begin{tabular}{lccccccccccc}
\hline \multirow{10}{*}{ Tratamentos } & \multicolumn{10}{c}{ Crescimento da raiz (mm)/Dias após a semeadura } \\
\cline { 2 - 12 } & 2 & 3 & 4 & 5 & 6 & 7 & 8 & 9 & 10 & 11 & 12 \\
\hline Controle & $33,4 \mathrm{bc}$ & $60,6 \mathrm{~b}$ & $75,0 \mathrm{a}$ & 54,0 ab & 40,2 & 25,0 & 23,0 & $23,0 \mathrm{c}$ & 30,4 & 38,0 bc & 44,6 \\
Ácido bórico & $38,8 \mathrm{ab}$ & $60,8 \mathrm{~b}$ & $77,8 \mathrm{a}$ & 52,0 ab & 45,0 & 35,8 & 45,0 & 40,6 a & 38,6 & 45,0 ab & 34,4 \\
Ulexita & $33,8 \mathrm{bc}$ & $73,2 \mathrm{a}$ & $82,8 \mathrm{a}$ & $53,4 \mathrm{ab}$ & 38,4 & 39,0 & 42,8 & $27,6 \mathrm{c}$ & 53,8 & 47,4 ab & 42,4 \\
Borogran & $48,2 \mathrm{a}$ & $73,4 \mathrm{a}$ & $81,6 \mathrm{a}$ & $59,8 \mathrm{a}$ & 48,2 & 45,8 & 38,3 & 34,8 ab & 31,8 & $29,8 \mathrm{c}$ & 37,0 \\
Yoorin B & $22,4 \mathrm{c}$ & $52,4 \mathrm{c}$ & $62,6 \mathrm{~b}$ & $44,2 \mathrm{~b}$ & 42,2 & 45,6 & 40,8 & 31,0 bc & 43,0 & $52,8 \mathrm{a}$ & 45,6 \\
\hline F (trat.) & $5,02^{* *}$ & $16,77^{* *}$ & $9,35^{* *}$ & $1,99^{\text {ns. }}$ & $0,89^{\text {ns. }}$ & $3,58^{\text {n.s. }}$ & $2,94^{\text {n.s. }}$ & $6,44^{* *}$ & 1,70 n.s. & $7,60^{* *}$ & $1,78^{\text {n.s. }}$ \\
C.V. (\%) & 26,44 & 7,73 & 7,94 & 16,8 & 21,52 & 26,42 & 12,09 & 18,88 & 24,34 & 16,97 & 20,04 \\
\hline
\end{tabular}

Obs. Letras diferentes nas colunas indicam diferença significativa pelo teste Duncan ao nível de 5\% de probabilidade.

NS não significativo pelo teste $\mathrm{F}$.

** significativo ao nivel de $1 \%$ de probabilidade pelo teste $\mathrm{F}$.

$\mathrm{O}$ desenvolvimento radicular promovido pelo Borogran e restringido pelo Yoorin B, com relação ao controle, pode ser observado na Figura 1. 


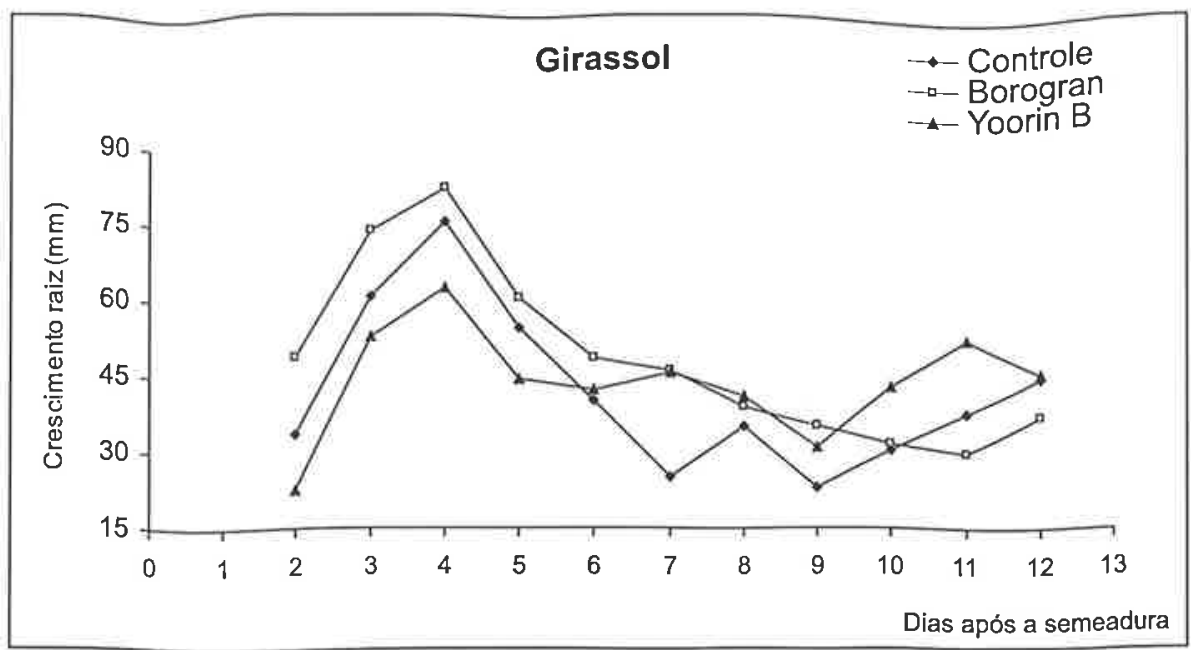

Figura 1. Mensuração do crescimento da raiz principal de girassol dos 2 aos 12 DAS em rizotrons com Borogran e Yoorin B, em relação ao controle.

Tratamentos com 3 ppm de boro na forma de Borogran e ulexita tenderam a aumentar o comprimento total das raízes de girassol para 484,67 e 481,33 mmm, respectivamente, sem porém diferir significativamente do controle $(443,50 \mathrm{~mm})$, como podemos observar pela Tabela 2.

Tabela 2. Comprimento total do sistema radicular de girassol, determinado 12 DAS.

Tratamentos Comprimento Radicular 12 DAS (mm)

Controle 443,50

Ácido bórico

475,17

Ulexita 481,33

Borogan 484,67

Yoorin B 424,17

$\mathrm{F}$ (trat.) $1,69^{\mathrm{NS}}$ 


\section{CONCLUSÕES}

1. O Borogran aplicado no substrato a $3 \mathrm{ppm}$ promove aumentos no crescimento das raízes de girassol.

2. O Yoorin B aplicado no substrato a 3 ppm causa diminuição no desenvolvimento radicular de Helianthus annuus.

\section{REFERÊNCIAS BIBLIOGRÁFICAS}

ALTMAN, A. \& U. BACHRACH., 1981. Involvement of Polyamines in Plant Growth and Senescence. In: Advances in Polyamine Research. C.M. Caldera; V. Zappia; U. Bachrach (Eds.). New York, Raven Press, III:365-375.

COKE, L. \& W.J. WHITTINGTON., 1968. The Role of Boron in Plant Growth. IV. Interelationships Between Boron and Indol-3yl-Acetic Acid in the Metabolism of Bean Radicles. J. Exp. Bot., 19:295308.

EATON, F.M., 1940. Interelations of the Effects of Boron and Indoleacetic Acid on Plant Growth. Bot. Gaz., 101:700-705.

GAUCH, H.G. \& W.M. DUGGER Jr., 1953. The Role of Boron in the Translocation of Sucrose. Plant Physiol., 28:457-466.

GORTER, C.J., 1958. Synergism of Indole and Indole-3-Acetic Acid in the Root Production of Phaseolus Cuttings. Physiol. Plant. 11:19.

HAISSIG, B.E., 1986. Metabolic Processes in Adventitious Rooting of Cuttings. In: New Root Formation in Plants and Cuttings. M.B. Jackson (Ed.). Dordrecht, Martinus Nijhoff Publ., 141-189.

HEMBERG, T., 1951. Rooting Experiments with Hypocotyls of Phaseolus vulgaris L. Physiol. Plant. 11:1-9.

JACKSON, M.B. \& P.M. HARNEY., 1970. Rooting Cofactors, Indoleacetic Acid, and Adventitious Root Iniciation in Mung

Cuttings (Phaseolus aureus). Can. J. Bot., 48: 43-946. JARVIS, B.C. \& A.H.N. ALI., 1984. Irradiance and Adventitious Root Formation in Stem Cuttings of Phaseolus aureus Roxb. New Phytol., 
97:31-36.

JARVIS, B.C. \& S. YASMIN. 1985. The Influence of Calcium on Adventitions Root Development in Mung Bean Cuttings. Biochem. Physiol. Pflanzen, 180:697-701.

JARVIS. B.C.; A.H.N. ALI. \& A.I. SHAHEED, 1983a. Auxin and Boron in Relation to the Rooting Response and Ageing of Mung Bean Cuttings. New Phytol., 95:509-518.

JARVIS, B.C.; P.R.M. SHANNON; \& S. YASMIN, 1983b. Influence of IBA and Cordycepim on Rooting and RNA Synthesis in Stem Cuttings of Phaseolus aureus Roxb. Plant Cell Physiol., 24:139146.

JARVIS, B.C.; P.R.M. SHANNON \& S. YASMIN, 1983c. Involvement of Polyamines with Adventitions Root Development in Stem Cuttings of Mung Bean. Plant Cell Physiol., 24:677-683.

JARVIS, B.C.; S. YASMIN.; A.H.N. ALI \& R. HUNT, 1984. The Interaction Between Auxin and Boron in Adventitious Root Development. New Phytol., 97:197-204.

KERSTEN, E., 1990. Efeito do Boro, Zinco e Ácido Indolbutírico no Enraizamento de Estacas de Dois Cultivares de Macieira (Prunus salicina, Lindl.). Piracicaba, 109p. Tese (Doutorado). Escola Superior de Agricultura "Luiz de Queiroz", Universidade de São Paulo.

LEWIS, D.H., 1980. Boron, Lignification and the Origin of Vascular Plants - a Unified Hypothesis. New Phytol., 84:209-229.

MENGEL, K. \& E.A. KIRKBY, 1982. Principles of Plant Nutrition.

Int. Potash Inst., Bern, Switzerland, p.444-450.

MIDDLETON, W; B.C. JARVIS \& A. BOOTH, 1978. The Boron

Requeriment for Root Development in Stem Cuttings of Phaseolus aureus Roxb. New Phytol., 81:287-297.

MIDDLETON, W.; \& B.C. JARVIS \& A. BOOTH, 1980. The Role of Leaves in Auxin and Boron-Dependent Rooting of Stem Cuttings of Phaseolus aureus Roxb. New Phytol., 84:251-259.

MURRAY, H.R.; C.D. TAPER, T. PICKUP \& A.N. NUSSEY. 1957. Boron Nutrition of Softwood Cuttings of Geranium and Currant in Relation to Root Development. Proc. Am. Soc. Hort. Sci., 69:498501.

NEATLES, T.F., 1960. Some Effects of Boron on Root Growth. 
Aust. J. Biol. Sci., 13:232-248.

ONO, E.O.; J.D. RODRIGUES \& S.D. RODRIGUES, 1992. Interações entre Auxinas e Boro no Enraizamento de Estacas de Camélia. Rev. Bras. Fisiol. Veg., 4:107-112.

PIMENTEL-GOMES, F., 2000. Curso de Estatística Experimental. $14^{\mathrm{a}}$ ed. Piracicaba, $480 \mathrm{p}$.

RIBAS, K.C., 1993. Efeito de Auxinas, Ácido Bórico e Suas Interações no Enraizamento de Estacas de Macadamia integrifolia Maiden \& Betche. Botucatu, 128p. Dissertação (Mestrado). Universidade Estadual Paulista Dr. Júlio de Mesquista Filho.

SHYR, Y. \& C. KAO, 1985. Polyamines and Root Formation in Mung Bean Hypocotyls Cuttings. Bot Bull. Acad. Sinica, 26:179-184. TISDALE, S.L. \& W.L. NELSON, 1966. Soil Fertility and Fertilizers. New York, The Macmillan Co. 694p.

WEISER, C.J., 1959. Effect of Boron on the Rooting of Clematis Cuttings. Nature, 183:559-560.

WEISER, C.J. \& L.T. BLANEY, 1960. The Effects of Boron on the Rooting of English Holly Cuttings. Proc. Am. Soc. Hort. Sci., 75:707-710. 